\title{
WSN for Appliance Control
}

\author{
Prof. Dr. Ram Joshi ${ }^{1}$, Aksha Gavate ${ }^{2}$, Sweety Gholap ${ }^{2}$, Sayali Kumar ${ }^{2}$, Sonali Patil ${ }^{2}$ \\ Savitribai Phule Pune University \\ ${ }^{1}$ Professor, ${ }^{2}$ Student, Department Information Technology, \\ JSPM's Rajarshi Shahu College of Engineering, Tathwade, Pune
}

\begin{abstract}
Solar energy is a very useful renewable source of energy, which may be the answer to the future for power, or energy needs, as global warming seems to pick up rapidly. We can reduce global warming problem by using solar energy thus diminishing or trimming down various gas emissions, which can damage earth, in turn, the millions of people in it. By installing solar lights in college premises, it will help to reduce the energy crisis. Arduino act as a main controller which connects various sensors and other modules. By using automatic turning on/off lights can also reduce the energy and will save the power. Using android application user can manually control lights. This application conjointly focuses on motion detection and darkness detection by providing security to application against unauthorized user. So, by installing Solar lights in college premises, it will help to boost the economy of India.
\end{abstract}

Keyword: Solar panel, solar battery, Arduino, PIR and IR sensor, LDR sensor, Bluetooth module.

\section{INTRODUCTION}

The increase of energy crisis everywhere over the planet has created problem which can be reduced by using solar energy. A method is to look at the new energy and profit of the renewable energy. Utilization of the new energy-saving technologies to scale back energy consumption, and improve utilization potency of energy. Alternative energy is the most direct, common, and clean energy. The star resources are often appeared inexhaustible. Alternative energy could be a helpful renewable supply of energy, which can be the solution to the long run for power, or energy wants. So, we will all contribute to the surroundings by victimisation alternative energy so erasing or trimming down numerous gas emissions, which may endanger earth.

Automation could be a technique or a way or a system in operation using electronic devices by reducing human involvement to a minimum. The elemental of building an automation system for a workplace or house is increasing day-by-day with sizable amount of advantages. Men of affairs, researchers and students square are working to make economical and affordability automatic systems to watch and manage totally different machines like lights, fans, AC supported needs. Automation is another necessary application of wireless technologies like Bluetooth, Wi-Fi. It's the observance of the energy consumption and therefore the dominant surroundings in buildings, schools, offices and museums by different kinds of sensors that manage lights, temperature, motions, darkness. To create it a lot of operative and economical, price is reduced by low price communication technology like Bluetooth.
Bluetooth could be a technology that permits the users fast connections between many devices in real time. The means of transmission used, assures protection against interferences and safety within the causing of data is up to one hundred meters. Building upon this theme; we tend to propose an electrical device which may be charged by solar energy, supported Bluetooth technology on the market in automaton smartphones.

Our paper presents Bluetooth based mostly centrally controlled home automation system victimisation smartphones and Arduino Uno board. Such a system can modify users to own management over lights like corridors with Bluetooth. All that the user wants is a smartphone, that is in virtually everybody's hand today, and an Arduino microcontroller circuit. The feedback circuit consists of an Arduino Uno microcontroller, that processes the user commands and controls the shift of devices. When darkness and movement is detected, light will automatically glow. The association between the microcontroller and therefore the smartphone is established via Bluetooth, a widespread wireless technology used for sharing knowledge. This application conjointly focuses on motion detection and darkness detection by providing security to application against unauthorized user.

\section{LITERATURE SURVEY}

Implementation of passive infrared sensor in street lighting automation system by N. L. Ramli, N. Mohd Yamin, Suliana Ab Ghani, N. Md. Saad and S. A. Md Sharif [December 2015]

In this paper the authors have projected a sensible street lighting system that provides a secure evening time setting for all road users and pedestrian. The most objectives were to create Associate in Nursing automation system of street lighting employing a low-priced microcontroller that is Arduino and to realize energy-saving. this technique required to be controlled in line with the particular mode. These modes square measure controlled by 2 devices that square measure lightweight Dependent resistance (LDR) and Passive Infrared (PIR) sensor. this technique will mechanically activate and off the lights in line with traffic flow. this technique operates throughout the night and therefore the focus is barely for the unidirectional road at a junction. Street lightweight are on once solely there's road user otherwise, it'll close up. This style will save an excellent quantity of electricity or energy consumption compared to standard street lights that keep alight throughout nights. 
Bluetooth based home automation system using cell phone by Rajeev Piyare, M. Tazil [June 2011]

In this paper the authors have advised the planning and implementation of an occasional value however nevertheless versatile and secure cell phone-based home automation system. the planning was supported a standalone Arduino BT board and therefore the home appliances square measure connected to the input/ output ports of this board via relays. The communication between the telephone and therefore the Arduino BT board was wireless. this technique was designed to be low value and scalable permitting type of devices to be controlled with minimum changes to its core. countersign protection was wont to solely enable authorised users from accessing the appliances reception. during this paper we tend to gift an occasional value secure telephone based mostly, versatile home automation system employing a secured communication between human and therefore the system, that's using a Bluetooth module.

PIR and IR sensor based smart home automation system using IOT for energy saving applications by P. Eben Sophia, Prithvirajan R., Thirunavukarasu S., Muthuraj K., $S$. Sarmila [June 2019]

In this paper the authors have put forth an provide automatic electronic appliance on/off using PIR sensor. This design was proposed using PIR sensor for automation of lights and fans using Arduino with Internet of Things for smart homes. The presence of PIR sensors ensured that the lights turn on and off according to motion it senses. This design represents the role of Arduino UNO board in controlling the operation of PIR sensor and electrical components in the framework. The Arduino gets a flag from PIR, which turns on the lights, fans or electrical appliances. Every single 40 seconds Arduino checks the signs from the PIR sensor and whenever it gets yield as '1' (high) then it won't cut-off the primary voltage and whenever it gets yield as ' 0 '(low) at that point the voltage is cut-off and the appliance terminates its functioning.

Solar powered LED-based lighting facilities by Patrizio Primiceri and Paolo Visconti [January 2017]

In this paper, the authors have reported on new technological trends and devices employed in construction of advanced solar powered LED based lighting systems, which can be used for both outdoor and indoor applications. This paradigm proved to be choicest in controlling and driving the LED-based lighting facilities, that can be provided of integrated sensors, thus realizing new lighting functionalities, improved management of the energy. Sun light can be converted into DC electricity when it falls on the top surface of the solar cells inside the PV module by means of photovoltaic conversion process. This system integrate SSL technology, low-cost sensors, smartphones and IoTbased devices and must fulfil the expectcation to facilitate new lighting functionalities and a great exchange of data among lighting systems, installed everywhere both inside or outside of buildings.

\section{RELATED WORK}

The solar panel is the core part of the solar light system which converts the sun's radiant energy to electrical energy, and then transmits through the controller to be stored in the battery. The battery which is connected to the Arduino and transmit the power while the light glows. It is basically comprising of four mechanism.

\section{1) Connection of Arduino with Solar system}

Arduino board module, facilitated with a solar panel and a battery, can power your Arduino project in two ways: either by connecting your Arduino board to the module and the module to its solar panel or by connecting the battery to the solar module then the solar module to your Arduino board via a pair of wires.

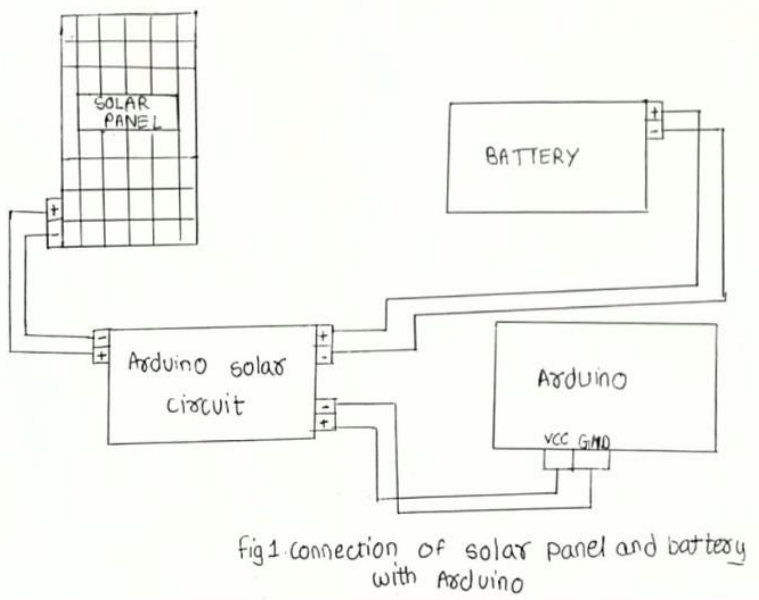

2) Connection of Arduino with Bluetooth

This Circuit is simple and small. The Arduino and Bluetooth module has only four connections.

Arduino pins --> Bluetooth pins

PX (Pin 0) ----> TX

TX (Pin 1) ----> RX

$5 \mathrm{~V}---->\mathrm{VCC}$

GND ----> GND

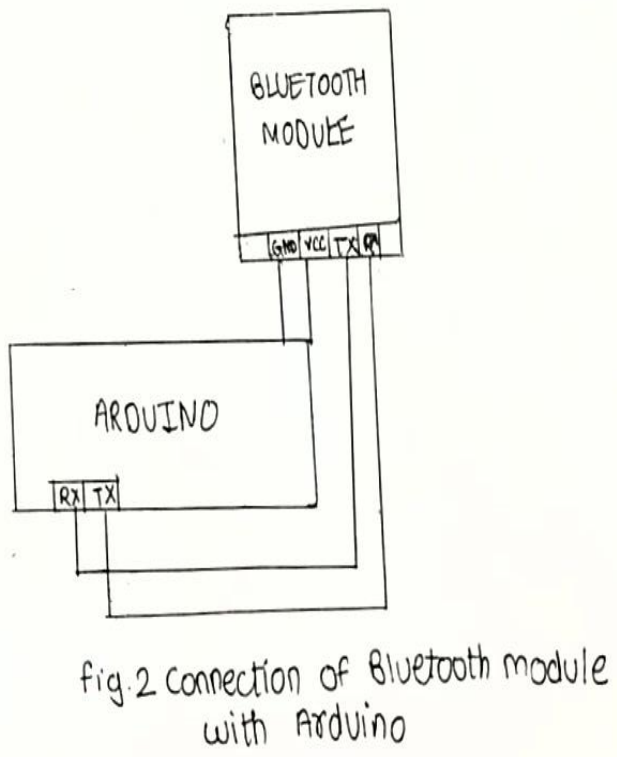




\section{3) Connection of Arduino with PIR and IR sensors}

The PIR Sensor and IR sensor detects movement in front of it and signals Arduino. Arduino will activate an alarm in the form of a Buzzer, whenever any movement is detected.

Connect the negative wire of the IR sensor and PIR sensor together and then connect to GND on the Arduino. Connect the middle of the IR and PIR sensors which is the VCC to $5 \mathrm{~V}$ on the Arduino.

Pin 8 of the Arduino is connected to the signal pin of the IR sensor.

4)Connection of Arduino with LDR sensor

The setup is very simple:

Connect $+5 \mathrm{~V}$ of the Arduino to one pin of the LDR Connect the other pin of the LDR to A0 and one pin of the $100 \mathrm{~K} \Omega$ resistor.

Connect the other pin of the $100 \mathrm{~K} \Omega$ resistor to GND of the Arduino.

\section{CONCLUSION}

However, the efficiency of the solar cells is increasing, while the price is decreasing. However, the efficiency of the solar cells is increasing, while the price is decreasing. At same time, the efficiency of the LED light is in a rapid increase, but the prices are lower. Automatic light control mechanism saves the power and energy. And it is step towards the automation world. So following development of the outdoor lighting technic, the solar LED light system has shown us it will have promising application and infinite vitality.

\section{REFERENCES}

[1] Daniel F. Butay, Michael T. Miller. "Maximum Peak Power Tracker: A Solar Application" April 24th, 2008.

[2] "Lab 1 - Electrical Characteristics of Photovoltaic Cells " School of Electrical and Information Engineering, University of Sydney. Semester 2, 2011.

[3] Pan Shiquan "Application Research in the Solar Street Lamp Management Based on the LED Light-emitting Diodes" Bulletin of Science and Technology, Vol.28 No.4 Apr.2012.

[4] P. Tenti. "Dispense del Corso di Elettronica Industriale". Università degli Studi di Padova. 2012

[5] T. Esram. "Comparison of Photovoltaic Array Maximum Power Point Tracking Techniques" Energy Conversion, IEEE Transactions on(Volume:22 Issue: 2 ). 2007. 